Estudios Públicos I64 (2021), 93-107

DOI: https://doi.org//0.38/78/07/83089/0902/05/3

Nota de investigación

\title{
Reflexiones sobre el poder legislativo: un ensayo fundacional de Andrés Bello
}

\author{
Iván Jaksić \\ Stanford University, Chile
}

\begin{abstract}
Resumen: Esta nota de investigación identifica la cronología exacta de la publicación de uno de los ensayos más importantes de Andrés BeIlo, "Publicidad de los juicios", que apareció en el periódico chileno El Araucano en 1830, pero que se publicó originalmente sin atribución de autor en El Censor Americano en Londres en 1820. En esta nota se establece la autoría de Bello y se arguye que entre ambas publicaciones hay algunas diferencias importantes, que evidencian momentos históricos diferentes: la crítica, con mirada inglesa, a la revolución liberal en España en 1820, que restauró la Constitución de 1812 y la organización republicana de Chile en 1830 . El elemento de continuidad es la transparencia de las decisiones judiciales, cualquiera sea el sistema político, monárquico-constitucional, o constitucional-republicano.
\end{abstract}

Palabras clave: Andrés Bello, poder legislativo, el Censor Americano, Constitución 1833, constitucionalismo hispanoamericano, libertad de prensa, voluntad general

RECIBIDO: marzo 2021 / ACEPTADO: agosto 2021

Thoughts on the Legislative Branch: Continuities in the Political Thought of Andrés Bello

ABSTRACT: This note traces the origins of Andrés Bello's influential essay on the importance of publication of judicial decisions, which appeared in the Chilean periodical El Araucano in 1830. The current research note demonstrates that the essay was originally published in the Lon-

IVÁN JAKSIĆ es historiador, premio Nacional de Historia 2020, director del Programa de la Universidad de Stanford en Chile, miembro de número y vicedirector de la Academia Chilena de la Lengua, y director de la Cátedra Andrés Bello de la Universidad Adolfo Ibáñez, Chile. Dirección: Stanford University, Santiago Program, Condell 189, Providencia, Santiago, Chile, CP 7500753. Email: ijaksic@stanford.edu. 
don periodical El Censor Americano in 1820, although without identifying Bello as the author. Despite the differences between the two versions, due to the different historical moments (the restoration of the Constitution of 1812 after the revolution of 1820 in Spain, and the republican organization of Chile in 1830), this note argues that there is a fundamental thread uniting the two essays, namely, the central importance of publishing judicial decisions in any political system, be it a constitutional monarchy, or a republic.

KEYwords: Andrés Bello, legislative branch, El Censor Americano, Constitution 1833, Spanish American constitutionalism, freedom of press, popular will

ReCEIved: March 2021 / AcCePted: August 2021

A ndrés Bello (1781-1865) no acostumbraba firmar sus propios ensayos, o bien, lo hacía solo con las iniciales A.B. Eso era congruente con una disposición retraída y modesta, pero también con un concepto de la autoría que no se basaba muy fuertemente en lo individual. Esto ha hecho difícil identificar algunos artículos que son propiamente de su pluma o, también, se le han atribuido algunos que quizás no lo son. A pesar de los esfuerzos titánicos de la comisión editora de las Obras completas de Andrés Bello, publicadas en Caracas a partir de 1951, quedan algunos vacíos que un cotejo cuidadoso de las fuentes puede ayudar a llenar; de este modo, se podrá hacer justicia a las labores de Bello y trazar con más precisión la cronología de sus ideas.

Una de las fuentes más importantes, pero menos conocida, es El Censor Americano, revista publicada en Londres en 1820. ${ }^{1}$ La evidencia más potente de la participación de Bello proviene de Antonio José de Irisarri, quien invitó al caraqueño a participar en la revista, que publicó solo cuatro números, y quien ratificó la participación de Bello en su correspondencia. Sin embargo, no se ha hecho todavía un análisis de cuáles y cuántos artículos son de la pluma de Bello. Algunos son bastante obvios, dado el origen y los conocimientos del autor, como por ejemplo aquellos sobre la vacuna; sobre Alexander von Humboldt, a quien conoció personalmente; o sobre la región venezolana de Cumaná, que visitaba con frecuencia. Otros no lo son tanto, pero el tenor de la revista refleja las preocupaciones políticas del momento, y que sabemos ahora eran las de Bello: la transición de la monarquía a la república, el momento constitucional, la

1 Existe una edición moderna de esta escasa fuente. Ver Jaksić (2019). 
organización política, las relaciones internacionales y la independencia hispanoamericana, para mencionar solo algunas de las principales.

\section{La pista de El Censor Americano}

En esta nota de investigación afirmo que el ensayo 'Reflexiones sobre el poder legislativo', publicado en el cuarto y último número de El Censor Americano (1820, 306-307), pertenece a Andrés Bello. Me baso para ello en el siguiente pasaje:

La publicidad de los juicios es igualmente necesaria; y a la verdad, bajo cualquier aspecto que la miremos se puede afirmar, que en lo benéfico de sus efectos no cede a ninguna otra institución política. Esta publicidad es el mejor freno contra la arbitrariedad de los jueces, y contra las prevaricaciones de los otros empleados en la administración de justicia. Ella pone de bulto la falsedad de los delitos, ${ }^{2}$ y da nuevo vigor a las leyes, amedrentando a sus infractores con la infamia, que no puede menos de acompañar a la convicción. ${ }^{3}$ Ella las hace inflexibles, precaviendo las consideraciones, los empeños, y otros arbitrios aún más criminales de que los poderosos se valen demasiadas veces para eludirlas. Ella ejerce una continua censura sobre las costumbres, y graba profundamente en los ánimos los principios de rectitud y honor. Pero aquí nos limitamos a considerarla como un medio de instruir a la nación en las reglas que la gobiernan, y de dar a conocer prácticamente su aplicación y su tendencia, los efugios con que se logra evadirlas, y los vicios, o defectos de que adolecen. ¿Qué espectáculo más instructivo para el futuro legislador que el que le presenta, no en aventuras imaginadas para divertir la imaginación, no en fríos tratados filosóficos, sino en su propio ser, y con sus nativos colores, la tentación que arma el brazo del malhechor, los lazos que la seducción tiende a la inocencia, las maquinaciones de la ambición y la avaricia contra el honor, la vida, y las propiedades de los ciudadanos?

Con frases idénticas, este párrafo se publicó en el periódico El Araucano, en el No 9 de noviembre de 1830. Miguel Luis Amunátegui lo incorporó al tomo IX de las Obras completas (edición chilena) en 1885, con el título de 'Publicidad de los juicios' (1-7), que fue recogido con posterioridad por la edición venezolana de las Obras completas (tomo XVIII) (19811984). Quedó así establecida la autoría de Bello, pero no se ha identifica-

\footnotetext{
${ }^{2}$ Este término figura claramente en la publicación original, que se puede consultar en la Biblioteca Nacional de Chile, pero fue posteriormente reemplazado por 'fealdad'. Es decir, 'la fealdad de los delitos'.

${ }^{3}$ El término 'convicción' puede ser ambiguo para el lector actual. Bello pareciera utilizarlo en el sentido de 'persuasión', es decir, el persuadirse del negativo efecto de la infamia antes de perpetrar un delito.
} 
do, hasta el momento, su proveniencia original, que se encuentra en el ejemplar de El Censor Americano y que constituye un antecedente importante para entender el contexto de las ideas de Bello. He aquí el texto de 1830, extraído de 'Publicidad de los juicios' (Bello 1981-1984a, 444):

La publicidad de los juicios, bajo cualquier aspecto que se mire, es, de todas las instituciones políticas, la más fecunda de buenos efectos. Ella es el único preservativo seguro de la arbitrariedad y de las prevaricaciones. Ella pone de bulto la fealdad de los delitos, y vigoriza las leyes, amedrentando a sus infractores con la infamia, que no puede menos que acompañar a la convicción. Ella las hace inflexibles, contraponiendo a las consideraciones, a los empeños, y a otros medios aún más criminales de que los poderosos se valen demasiadas veces para eludirlas, la fuerza invencible de la opinión pública, que ejerce una judicatura suprema, que lo ve todo, que escudriña la conciencia misma de los jueces, y a cuyos fallos no puede sustraerse autoridad alguna. Ella ejerce al mismo tiempo una censura vigilante sobre las costumbres y graba profundamente en los ánimos los principios de rectitud y honor. Ella es uno de los mejores medios de instruir a la nación en las reglas que la gobiernan, y de dar a conocer prácticamente su aplicación y su tendencia, los efugios con que se logra a veces evadirlas, y los defectos o vicios de que adolecen. ¿Qué espectáculo más instructivo y más útil que el que presenta a los ciudadanos, no en aventuras imaginarias, no en frías lecciones de moral sino en su propio ser y con sus nativos colores, la tentación que arma el brazo del malhechor, los lazos que la seducción tiende a la inocencia, las maquinaciones de la ambición y la avaricia contra el honor, la vida y las propiedades de los ciudadanos?

Con todo, hay diferencias importantes entre ambos artículos, que revelan la evolución del pensamiento político de Bello entre 1820 y 1830. Se trata de una década crucial tanto en la vida del autor como en la historia política de Europa e Hispanoamérica. Esta es la época del surgimiento de un nuevo orden mundial tras las guerras napoleónicas; de las independencias hispanoamericanas, y de nuevas tendencias políticas y literarias como el romanticismo y el nacionalismo. En la vida de Bello se observa el tránsito desde una adhesión a la monarquía constitucional hasta la aceptación pragmática de la existencia de las repúblicas. Es también una época de penurias, pero también de enorme creatividad, que culmina con su traslado a Chile en 1829.

El ensayo de 1820 tiene como trasfondo la revolución liberal de ese año en España, que restauró la Constitución de 1812 e inauguró el denominado 'trienio liberal' (1820-1823). Bello era particularmente crítico de esta Constitución, por la magra representación que otorgaba a las 
provincias hispanoamericanas. Pero sobre todo era crítico del concepto de 'voluntad general' y de la ley como expresión de ella. Para Bello, la voluntad es cambiante, mientras que la ley ('fija y estable') debe estar clara e inequívocamente orientada al 'interés general'. En el artículo, rechaza la idea de la soberanía popular, puesto que un pueblo sin educación no puede discernir cuál es el interés común, motivado como está por pasiones 'imperiosas' e 'inmoderadas'. El camino correcto, según Bello, es la elección de representantes genuinamente motivados por el bien común, y cuyas acciones tendrán el contrapeso de una prensa libre y una judicatura proba y transparente. De aquí el énfasis en la publicidad de los juicios, claramente argumentada en el párrafo mencionado de 1820. Importa señalar que estos comentarios se remiten a la situación de España y no contempla casos hispanoamericanos, salvo para enfatizar la baja credibilidad de la resurrecta Constitución de 1812 en materias de representación.

El contexto del artículo de 1830 es diferente. Bello llegó a Chile en junio de 1829, en pleno período de la crisis política que desembocó en la Guerra Civil de 1829-1830. La independencia hispanoamericana había sido reconocida, aunque selectivamente, por Gran Bretaña y Estados Unidos. El modelo político no era la monarquía, sino la república, pero la organización política era un tema de continuo debate y conflicto. En la publicación de noviembre de 1830, Bello advierte que la ley constitucional no debe estar guiada por 'principios abstractos.' Hispanoamérica se ha visto en la ingrata situación de obtener la independencia sin tener tradiciones como la libertad de imprenta o los juicios por jurados, con los que contaba la revolución norteamericana. Construyó por ende su organización política a partir de escasos materiales y para 'crearlo todo'. Las constituciones hispanoamericanas tenían poca tradición, pero era ya "demasiado tarde para empezar de nuevo", agregando que "todo lo que está a nuestro alcance es estribar las constituciones existentes y mejorarlas por los medios que ellas mismas proporcionan". Es por eso que, pensando específicamente en Chile, era necesario mantener "a toda costa" la Constitución existente, "mejorándola progresivamente, y sobre todo acomodando a ella las demás partes de nuestra organización política". Es en este nuevo contexto, a diferencia del de 1820, que Bello aplicó el idéntico principio de la publicidad de los juicios, dado que "el freno de la opinión pública" era necesario, en todo momento, para "aquellos fun- 
cionarios a cuya custodia están encomendadas las vidas, la hacienda [y] el honor de los ciudadanos". Este es un pilar del pensamiento de Bello y representa un punto de continuidad entre ambos ensayos.

\section{Andrés Bello y la Constitución de 1833}

No cabe duda de que Bello tuvo participación en la Constitución de 1833. Así lo afirmó Diego Portales, a la sazón ministro todopoderoso del gobierno de Joaquín Prieto. Bello prefirió, sin embargo, no referirse a ello, en parte porque pensaba que lo importante eran las leyes, es decir, "reglas ciertas, fijas [e] inmutables". A poco andar, se volcaría de lleno a la redacción de una nueva legislación civil. Sin embargo, como funcionario público y parte del gobierno, Bello se pronunció respecto de la Constitución para apoyarla, no como un documento totalmente nuevo, sino como 'reforma' del documento existente, es decir, la Constitución de 1828. Su escueta definición del papel de las constituciones era el de "determinar las condiciones del pacto social", lo cual consideraba como logrado con la actual reforma, señalando que el "principal empeño" de los constituyentes,

ha sido combinar un gobierno vigoroso, con el goce completo de una libertad arreglada; es decir, dar al poder la fuerza para defenderse contra los ataques de la insubordinación, producida por los excesos de la democracia, y proporcionar a los pueblos y a los hombres recursos con que preservarse del despotismo. ${ }^{4}$

La cautelosa defensa de Bello de esta Constitución, pero al mismo tiempo su significado central, se resume en el mensaje del presidente Joaquín Prieto en 1834 (redactado por Bello): “El código constitucional no tiene valor sino en cuanto apoya sólidamente las buenas instituciones civiles, y es sin ellas un andamio inútil, que el primer sacudimiento derribaría, y cuya caída no merecería llorarse" (Prieto, en Bello 1981-1984).

Los primeros embates importantes en contra de la Constitución de 1833 se produjeron hacia fines de la década de 1840, si bien esta no sería modificada sino hasta el último tercio del siglo, y reemplazada finalmente en 1925. El debate ocurrido en la década de 1940 se dio en el contexto de una polémica sobre la filosofía de la historia, en la que descollaron

\footnotetext{
${ }^{4}$ Las citas anteriores provienen de 'Reformas a la Constitución', en Bello (1981-1984b, 8592). Fue originalmente publicado en El Araucano entre mayo y junio de 1833.
} 
José Victorino Lastarria y Jacinto Chacón. Estos últimos argüían que las constituciones eran el reflejo del fondo, o corazón, de la sociedad, lo que no era precisamente un elogio, puesto que las costumbres chilenas mostraban a un pueblo aplastado ('anonadado') por el legado colonial. La filosofía de la historia demostraba tal hecho y señalaba un camino de liberación y de progreso. Esto llevó a Bello a pronunciarse una vez más respecto de las constituciones escritas. "Nos causa no poca sorpresa", señaló, "que en este año de 1848, después de tantos experimentos constitucionales abortivos, haya personas que consideren las constituciones escritas como esencial y constantemente emanadas del fondo de la sociedad." Es decir, no concedía el punto, preguntando, "una forma gubernativa chilena que copia la de Buenos Aires, la cual a su vez es una copia de la Revolución Francesa, ¿de qué corazón ha salido?". Quería subrayar el alcance limitado de las constituciones, así como el de sus orígenes y del tiempo necesario para su consolidación:

\begin{abstract}
Veamos los hechos como son; hablemos el lenguaje del sentido común. Las constituciones son a menudo la obra de unos pocos artífices, que unas veces aciertan y otras no; no precisamente porque la obra no haya salido del fondo social, sino porque carece de las calidades necesarias para influir poco a poco en la sociedad, y para recibir sus influencias, de manera que esta acción recíproca, modificando a las dos, las aproxime y armonice. ${ }^{5}$
\end{abstract}

Bello no era enemigo de las constituciones, pero consideraba que su proliferación, y frecuente fracaso, obligaba a buscar otras fuentes para la estabilidad política y social. Su visión negativa se refería a la Constitución española de 1812, y a las diversas 'teorías abstractas' que buscaban moldear a la sociedad. Su mirada era en muchos sentidos una mirada desde Gran Bretaña, país que no requería de una constitución escrita para garantizar ciertas libertades e imponer ciertas obligaciones. Una vez en Hispanoamérica, entendió que las constituciones escritas tenían una realidad insoslayable, pero intentó dar un papel mayor a las leyes civiles y a las funciones del poder legislativo. El hilo conductor que une estas dos etapas es precisamente la publicidad de los juicios, con la consecuente libertad de prensa y expectativas de probidad por parte de los funcionarios públicos.

\footnotetext{
${ }^{5}$ Las citas provienen de 'Constituciones', en Bello (1981-1984c, 253-261). Originalmente publicado en El Araucano, el 11 de febrero de 1848.
} 


\title{
3. El texto original
}

\author{
Dado que se trata de un texto prácticamente desconocido, que requiere \\ de mayor análisis, se reproduce aquí en su integridad:
}

\section{Reflexiones sobre el poder legislativo}

Si es cierto, como establece el filósofo de Ginebra, en su antisocial Contrato, que la ley es, o debe ser la expresión de la voluntad general; si este principio que los liberales han heredado de los Jacobinos, es una verdad de primera evidencia, un axioma político; un sistema legislativo será tanto mejor, cuanto más fielmente representada se halle en él esta voluntad general, a quien solo pertenece hacer leyes; y aquel únicamente será perfecto, que siga y represente hasta los menores movimientos y fluctuaciones de la mente soberana del pueblo. Admitido como verdadero el principio, no hay arbitrio para rechazar la consecuencia; y recíprocamente, si se prueba que la consecuencia es tan contraria a la razón, como a la experiencia de todos los siglos, será necesario confesar que el principio es absurdo, y desterrarle para siempre de la política.

Debemos sentar desde luego, que la conformidad de la ley con la voluntad general, si en esta sola reside el derecho de dictarla, no es susceptible de excepción, restricción o modificación alguna. Si hay un momento en que la voluntad general y la ley vayan por diversos caminos, en este momento es forzoso admitir que hay en la constitución del Estado un poder intruso, que promulgando sus decisiones como leyes, tiraniza. Es verdad que la constante conformidad de la ley con la voluntad del pueblo no puede reducirse rigorosamente a la práctica. Pero nada nos impide que le demos una existencia hipotética. Supongamos que se lograse dar a un pueblo instituciones bastante perfectas, para que se realizase aquel bello ideal del liberalismo; de modo que no hubiese negocio, ni hubiese instante en que la ley se diferenciase de la voluntad general. Si la razón demuestra, que este orden de cosas sería el más funesto para la sociedad, es evidente que la ley no debe consistir en la conformidad de que hablamos; porque una vez que el objeto de todo gobierno es la felicidad de los súbditos, todo principio contrario a ella es políticamente falso.

Esto sentado tratemos de indagar, qué es la voluntad general. ¿Será la unanimidad de todos los individuos de que se compone la nación? Esta unanimidad es imposible de obtener; porque apenas se presentará cuestión tan sencilla, sobre que no haya variedad de opiniones. Si se designa, pues, con aquellas palabras alguna cosa real, es necesario que sea la voluntad del mayor número, que es en substancia lo que llamamos vulgo. ¿Y cuáles son los caracteres de la voluntad de este mayor número? O miente la experiencia de todos los siglos, junto con la nuestra propia, (si es que tenemos abiertos los ojos a lo que pasa alrededor de nosotros) o no hay entidad posible, a quien menos convengan las funciones de la soberanía, y cuyos actos sean menos a propósito para convertirse en leyes. La ley, 
para que sirva de regla a las acciones humanas, debe ser fija y estable, y la voluntad de este mayor número es una veleta, que a cada soplo muda de dirección, y que recorre a veces en pocas horas todo el círculo de los vientos. La ley, como destinada a dirigir los complicados negocios de la sociedad, debe emanar de una mente sabia y calculadora: ¿no sería ridículo dar estos atributos al vulgo? El legislador debe ser circunspecto; y el vulgo es temerario y precipitado. Las miradas del legislador deben abrazar lo pasado y lo futuro; las del vulgo están circunscritas a lo presente, y aun los objetos, que tiene a la vista, le deslumbran; la superstición, la ignorancia, las preocupaciones se los muestran con falsos colores, y se los desfiguran a cada paso. Finalmente, la ley es la razón aplicada al gobierno de la sociedad, al equilibrio de los intereses y pasiones de los diversos elementos que la componen; y la voluntad general no es otra cosa, que la preponderancia momentánea de uno de estos intereses o pasiones.

Si hay, pues, algo de cierto en el mundo, es que una autoridad legislativa, que expresase rigorosamente la voluntad general, sería la peor, porque sería la más caprichosa, la más inconstante, la más ciega de todas. En una nación regida por ella no habría nada seguro ni estable, sino el imperio de preocupaciones antiguas; el Estado no haría más que pasar continuamente de un extravío a otro; y la administración presentaría una serie de oscilaciones y vaivenes, que sacudirían hasta las bases del orden social. Los hombres, cuyas medidas se aplaudiesen hoy, serían detestados y proscritos mañana. Y en efecto; ¿qué otra cosa es lo que se ha visto y se ve en los Estados, que han tenido la desgracia de dar demasiado influjo a la voluntad general en las deliberaciones legislativas? Si para hacer leyes benéficas bastase consultar la voluntad general, si ellas no fueran, como se pretende, sino la expresión de esta voluntad, es claro que no se podría darla demasiado influjo. Demostrando, pues, la razón, que las leyes dictadas por ella envolverían a la sociedad en un caos, y manifestando al mismo tiempo la experiencia, que cuando en el régimen del Estado no hay algún principio de reacción o de resistencia a las pasiones imperiosas de la multitud, a los actos desordenados de la voluntad general, todo es confusión y anarquía, ¿no es una consecuencia forzosa, que, o no debe asignársele parte alguna en la formación de las leyes, o que a lo menos debe oponérsele alguna fuerza que atempere sus excesos y contrarreste su violencia?

Pero en un gobierno representativo, se dirá, la prudencia y circunspección de los delegados del pueblo resistirá a los caprichos e injusticias de la multitud mal aconsejada. Concedámoslo: ¿no se sigue de aquí, que las providencias de este gobierno, para ser atinadas, deben desentenderse de los clamores del pueblo, cuando animado de pasiones inmoderadas, solicita injusticias? ¿Y qué conformidad habrá entre estas providencias y la voluntad general? ¿Y cómo puede llamarse voluntad general, y fuente de la ley, la que en la constitución del Estado está sujeta a ser examinada, modificada y resistida? El soberano en este caso, y el verdadero legislador no es la multitud, no es la pluralidad de los votos de los ciudadanos, sino el cuerpo representativo, que obedece o resiste a sus comitentes, según conviene, o según se le antoja. 
Para dar, pues, algún sentido racional a la proposición que analizamos, es menester interpretarla así: la ley debe ser la expresión de la voluntad de ciertos hombres, elegidos por el pueblo, el cual, conociendo su incapacidad para ejercer la soberanía, consiente en depositarla en personas de su confianza, que piensen y quieran por él, y a cuyas decisiones empeña implícitamente su obediencia, aun cuando sean contrarias a su voluntad propia. Pero ni aun es verdad que el pueblo ejerza este acto importantísimo de soberanía, nombrando él mismo sus diputados. Porque ¿cuál es el Estado en que los electores de la representación nacional forman una pluralidad de la nación? ¿Qué constitución hay tan democrática que no excluya de las elecciones las clases ínfimas, que son las más numerosas? Y con justa razón, si no se quiere aventurar el acierto en una materia de tanta trascendencia. Así es que ninguno de los Gobiernos representativos modernos procede sobre el principio de la soberanía del pueblo, ni de la conformidad de la ley con la voluntad general. En ninguna parte es el mayor número quien dicta la ley, ni quien elige a los legisladores delegados. En prueba de ello, veamos qué es lo que sucede en una revolución popular. Lo primero de que se trata es de fijar las formas constitucionales. Para ello se llama, es verdad a ciertos personajes revestidos del pomposo título de representantes del pueblo. ¿Pero es el pueblo, por ventura, quien los llama? No, sino los hombres que a la sazón se hallan a la cabeza del Estado. Estos son los que prescriben las reglas que se han de observar en su nombramiento, reglas, que excluyen de las funciones electivas a la pluralidad de la nación, y que limitan el voto pasivo a ciertas calidades de nacimiento, edad y fortuna. Si el pueblo es soberano, este primer paso de todas las constituciones es nulo de derecho, y todo cuanto recaiga sobre él es igualmente nulo. ¿Para qué, pues, hemos de admitir un principio absurdo en la teórica, inaplicable a la práctica, y no menos propio para despedazar a las democracias, que para hacer vacilar los tronos?

Reduzcamos las cosas a su justo valor. El gran problema de la organización de un cuerpo legislativo, no es hacer que la ley se conforme siempre con la voluntad, sino con el interés general. Para esto uno de los mejores medios, que ha descubierto la experiencia, es que no pase ninguna ley, a que no concurra el voto de un cuerpo numeroso, no de representantes del pueblo propiamente tales, sino de personas idóneas para tan difícil encargo, de cualquier modo que sean elegidas. Esta idoneidad supone cierta educación, cierta independencia personal; las formas electivas no tienen otro objeto que asegurarla; y aquellas serán mejores, que más cierta y completamente la aseguren en circunstancias dadas. Así que, estas formas nada tienen que ver con los principios abstractos, sino con el estado de la nación para quien se prescriben.

La constitución de este cuerpo debe ser tal, que proteja eficazmente los derechos de todos los ciudadanos, incluso aquellos que no tienen sufragio activo ni pasivo en las elecciones, los cuales forman por precisión el mayor número. Pero esto reduce cabalmente la masa del pueblo al estado de un menor, a quien es necesario nombrar curadores. Por el mismo principio que se niega uno y otro sufragio a las mujeres y a los niños, se priva 
de gozarlos a una multitud de hombres adultos, a quienes se puede decir, que la naturaleza, por la condición en que los hizo nacer, ha condenado a un pupilaje perpetuo.

El pueblo por consiguiente no es soberano, sino en el mismo sentido en que lo sería un Monarca demente, o fatuo, cuya autoridad estuviese en manos de una regencia que gobernase a su nombre. En los Estados más populares, el pueblo, la multitud, el vulgo, es verdaderamente un Rey maniatado, cuya corona es la irrisión de los que la sirven. Verdad es que esta Majestad deprimida suele a veces, en un arrebato de furia, romper sus cadenas y hacerse un objeto de terror. Pero al fin será necesario volverle a la jaula. La quietud pública y el bien mismo de su Majestad lo exigen.

El determinar aquel grado de la escala social, en que los ciudadanos empiezan a gozar de la facultad de elegir y de ser elegidos, es un punto dificultoso y delicado, pero que se arreglará en todos casos, si se quiere arreglarlo bien, por razones de conveniencia e interés público, concediendo estas facultades a solos aquellos que se supone pueden usarlas en utilidad común. Por consiguiente el interés de la sociedad es el verdadero principio a que debe conformarse la ley; o en otros términos, el bien público es la ley suprema, de que todas las otras no son más que consecuencias y aplicaciones. ¿De qué sirve decirnos, que el pueblo es el soberano, y que la ley es la expresión de su voluntad, si se añade a renglón seguido, que es necesario restringir su soberanía, para que de ella no resulte la ruina del Estado, y resistir sus deseos cuando se dirigen al mal? ¿No es esto reconocer una autoridad superior a la del pueblo?

Luego para juzgar, si un cuerpo legislativo es bueno o malo, no debemos preguntar, si representa o no la voluntad general. Lo que importa saber es, si está constituido de manera, que en sus decisiones no lleve otra mira que el bien público. A este fin es necesario que sus individuos tengan suficiente capacidad, suficiente independencia personal, y que en lo posible sean superiores a las tentaciones, a que se halla expuesto un poder tan grande, como el que les confiere la constitución. Consideremos estos tres puntos separadamente.

De nada servirá que los electores estén animados del mejor deseo de nombrar individuos capaces, si las circunstancias en que se halla la nación son tales, que no es fácil encontrar bastante número de sujetos ilustrados, o no es posible conocerlos. El primer objeto, pues, de una buena constitución es facilitar la adquisición de los conocimientos que exige la administración de los negocios públicos; y uno de los medios, que desde luego se presentan para conseguir este importante fin, es la libre discusión de los asuntos políticos por medio de la prensa. Esta libertad, sin embargo, es difícil de establecer, donde hay una administración de justicia que dependa del gobierno, o del cuerpo legislativo. Para no perdernos en especulaciones abstractas, contraigámonos a la nación española. Nadie negará que las Cortes, aunque no ejercen inmediatamente la administración de justicia, tienen demasiado influjo en ella. Supongamos que un autor divulga opiniones contrarias a las del partido, que a la sazón predomina en este cuerpo, y que es acusado de esparcir escritos sediciosos. El Tribunal, 
a quien tocase juzgarle, propendería naturalmente a la condenación del autor, para no exponerse al desagrado de las Cortes; cuyas resoluciones serán tanto más arbitrarias y parciales en casos de esta especie, cuanto es más difícil definir con exactitud, qué es lo que constituye sedicioso un escrito. ¿Podrá en semejante estado de cosas atreverse nadie a denunciar al público los errores o crímenes de una legislatura? ¿Podrá tachar de injusto o pernicioso alguno de los artículos del código constitucional? ¿Osará revelar los manejos secretos, los medios de corrupción, que si hoy no existen en las Cortes, pueden tal vez contaminarlas mañana? En vano, pues, será promulgar la libertad de la imprenta, donde no haya administración de justicia independiente; y claro está, que no puede haberla, donde los magistrados constituidos por el Gobierno pronuncien al mismo tiempo sobre el hecho y sobre el derecho. La institución de los jurados es lo único que puede salvar este inconveniente; porque en esta especie de juicio los que califican el hecho, no están revestidos de una magistratura lucrativa, que sentirían perder, ni son responsables de sus decisiones, más que a su conciencia, y a la opinión pública.

La publicidad de los actos del gobierno, y particularmente del cuerpo legislativo, la discusión de materias políticas en las corporaciones y sociedades, la popularidad de las elecciones, los establecimientos de educación para las clases pobres y humildes, son otros tantos objetos de primera importancia en un gobierno representativo. La frecuencia de las sesiones secretas de un Congreso es un grave mal, no solo porque disminuye la influencia de la opinión pública sobre la conducta de sus miembros, sino porque substrae al conocimiento de la nación noticias importantes sobre aquellos mismos asuntos que más le interesan, y que regularmente son los que se ventilan en semejantes sesiones. Es esencial que la nación se instruya a fondo de todos los datos y antecedentes que motivan las decisiones de la legislatura. ¿Pues cómo se podrá llenar este objeto, donde las funciones más importantes del cuerpo, que vela sobre la observancia de las leyes y la salud del Estado, se cubren bajo el velo del misterio?

La publicidad de los juicios es igualmente necesaria; y a la verdad, bajo cualquier aspecto que la miremos se puede afirmar, que en lo benéfico de sus efectos no cede a ninguna otra institución política. Esta publicidad es el mejor freno contra la arbitrariedad de los jueces, y contra las prevaricaciones de los otros empleados en la administración de justicia. Ella pone de bulto la falsedad de los delitos, y da nuevo vigor a las leyes, amedrentando a sus infractores con la infamia, que no puede menos de acompañar a la convicción. Ella las hace inflexibles, precaviendo las consideraciones, los empeños, y otros arbitrios aún más criminales de que los poderosos se valen demasiadas veces para eludirlas. Ella ejerce una continua censura sobre las costumbres, y graba profundamente en los ánimos los principios de rectitud y honor. Pero aquí nos limitamos a considerarla como un medio de instruir a la nación en las reglas que la gobiernan, y de dar a conocer prácticamente su aplicación y su tendencia, los efugios con que se logra evadirlas, y los vicios, o defectos de que adolecen. ¿Qué espectáculo más instructivo para el futuro legislador que el que le presenta, 
no en aventuras imaginadas para divertir la imaginación, no en fríos tratados filosóficos, sino en su propio ser, y con sus nativos colores, la tentación que arma el brazo del malhechor, los lazos que la seducción tiende a la inocencia, las maquinaciones de la ambición y la avaricia contra el honor, la vida, y las propiedades de los ciudadanos?

No es necesario detenernos a probar los buenos efectos de las discusiones de asuntos políticos en juntas de agricultores, comerciantes, artistas, vecinos, siempre que estas juntas se celebren públicamente, definido de antemano su objeto, y con intervención de algún magistrado, que pueda en caso necesario tomar providencias oportunas para precaver todo desorden. Estas discusiones despiertan la atención del público a las materias que tienen conexión con el régimen del Estado, y con la prosperidad de los varios ramos de industria, excitan los talentos, y les proporcionan darse a conocer. Lo mismo decimos de las sociedades particulares. Sabemos que las Cortes han empezado a mirarlas con desconfianza, y que algunas de ellas han dado justos motivos de inquietud a este cuerpo, y de temor al público. Pero todo tiene sus límites; y el querer suprimirlas enteramente sería tanto más arriesgado, cuanto difícil efectuarlo sin tocar a la libertad del ciudadano, y violar el asilo doméstico.

¿Y quién habrá que ignore lo conveniente de la popularidad de las elecciones para asegurar su pureza y acierto? Los autores de la Constitución Española no consultaron, cuando se trató de las formas electivas otro principio, que el de la soberanía del pueblo, y creyeron salvarle estableciendo aquella serie de colegios electorales, que nacen unos de otros, y teniendo por base los vecinos de las parroquias, acaban como en punta en el diputado o diputados, que se nombran por los electores de partido en cada capital de provincia. Pero la conexión de estos diputados con los vecinos de las parroquias, esto es, con la masa de los ciudadanos, es una cosa puramente metafísica, y una vana fantasma de representación popular; porque lo que hay de cierto es, que cada miembro de las Cortes ha sido casi siempre constituido por menos de una docena de votos. ¿No sería mucho mejor que se concediera a las ciudades cierto número de representantes, en razón de su población, o riqueza, los cuales fueran elegidos inmediatamente por el vecindario, sin excluir a las provincias de enviar otros miembros elegidos, como los de Condados en Inglaterra? De esta manera no solo serían representados los individuos, sino las clases, y tendrían las propiedades en las Cortes la influencia que debe dárseles en todo congreso legislativo. Pero el sistema de las Cortes es particularmente vicioso en cuanto quita a los hombres de mérito una de las mejores ocasiones de darse a conocer, y de recibir, en los aplausos y en el testimonio público de la confianza de sus ciudadanos, el premio más glorioso de la virtud y del talento.

En España, aún antes de esta última revolución, se había tratado ya por el gobierno de proporcionar a las clases inferiores los medios de su educación, y entendemos que se han fundado algunas escuelas de enseñanza mutua. Pero desearíamos saber si hasta ahora han pensado las Cortes en crear iguales establecimientos en América, en donde, sin duda 
alguna, se necesitan más. ${ }^{6}$ Esto ya se ve que toca a los diputados americanos el proponerlo, y apenas podrían agitar medida alguna que los haga más acreedores a la gratitud de su patria, que la de diseminar en aquel vasto hemisferio estos benéficos establecimientos. Estamos seguros de que harían mejor uso de su voto en las Cortes, si en lugar de sus infructuosas gestiones para que se dé a la América el número de diputados que le corresponde (y que aunque se le concediese no curaría los vicios radicales del sistema) se dedicasen a sacar de su débil influjo aquellas ventajas, que el partido dominante no quiera, o no se atreva a rehusarles.

Tales son los medios, que en los Gobiernos representativos, excitan continuamente el examen y discusión de los asuntos políticos, ilustran la opinión del pueblo, desenvuelven y hacen brillar los talentos, que tal vez por falta de ocasiones permanecerían desconocidos al mundo y aun a sí mismos, y sobre cada cuestión que se presenta, suministraran las noticias necesarias para decidir con acierto. Sin ellos no hay verdadera representación nacional, y sería poco decir, que la opinión pública no tiene influjo, porque en realidad no existe. Ellos, al paso que hacen conocer sus verdaderos intereses, hacen conocer a los legisladores los votos de la nación. Un Gobierno, pues, que merece el título de liberal, tratará de crearlos y multiplicarlos, y si por el contrario sus providencias conspiran a sofocar los que hay, o los que empiezan a desarrollarse, podemos estar seguros de que no lo es, sino en el nombre.

\section{Conclusiones}

Andrés Bello no deja de sorprender. Lo que revela este temprano ensayo es el nivel de los conocimientos adquiridos durante el período de Londres (1810-1829). Ellos son en parte teóricos, producto de sus lecturas, pero también de su experiencia observando la influencia de la prensa británica en los asuntos públicos, y en particular su escrutinio del desempeño de los funcionarios del gobierno y de los representantes en el parlamento. El papel de la prensa, y la transparencia de las decisiones públicas, son los principios fundamentales que Bello llevará consigo a Chile. El ensayo de 1820 se refiere específicamente a España, pero revela además un alto nivel de conocimiento político. Si además se considera que escribe estas líneas mientras desarrolla ideas literarias, escribe sus poemas fundacionales e investiga en los archivos del Museo Británico, debemos considerar que el período londinense fue particularmente formador y creativo. Cuando llega a Chile en 1829, trae consigo no solo los

\footnotetext{
${ }^{6}$ Precisamente por esos días, Bello había entregado un informe sobre el sistema lancasteriano de educación a Antonio José de Irisarri. Véase carta de Bello a Irisarri, del 11 de septiembre de 1820 (Bello, 1981-1984d, 613-615).
} 
materiales con los que realizará múltiples publicaciones, sino también una experiencia que le permitirá hacer aportes decisivos en la consolidación del orden republicano en Chile.

\section{Bibliografía}

Bello, A. 1981-1984. Obras completas. 26 tomos. Caracas: Fundación La Casa de Bello.

Bello, A. 1885. Publicidad de los juicios (1-7). En Bello, A., Obras completas, tomo IX. Santiago: Impreso por Pedro G. Ramírez.

Bello, A. 1981-1984a. Publicidad de los juicios (439-446). En Bello, A., Obras completas, tomo XVIII. Caracas: Fundación La Casa de Bello.

Bello, A. 1981-1984b. Reformas a la Constitución (85-92). En Bello, A., Obras completas, tomo XVIII. Caracas: Fundación La Casa de Bello.

Bello, A. 1981-1984c. Constituciones (253-261). En Bello, A., Obras completas, tomo XXIII. Caracas: Fundación La Casa de Bello.

Bello, A. 1981-1984d. A Antonio José de Irisarri, 11 de septiembre de 1820 (613-615). En Bello, A., Obras completas, tomo XXII. Caracas: Fundación La Casa de Bello.

El Censor Americano 1820. № 4 (octubre), 306-307.

Jaksić, I. (ed.) 2019. El Censor Americano. Santiago: Biblioteca Nacional de Chile, Centro de Investigaciones Diego Barros Arana.

Prieto, J. 1981-1984. Discurso del Presidente de la República a las Cámaras Legislativas en la apertura del Congreso Nacional de 1834. En Bello, A., Textos y mensajes de gobierno (47-57), Obras completas, tomo XIX. Caracas: Fundación La Casa de Bello. EP 